\title{
Therapeutic Follow-Up of Postoperative Patients on Tramadol in the Intensive Care Unit a Tertiary African Hospital: A Cohort Study
}

\author{
Metogo Mbengono JA ${ }^{1}$, Owono Etoundi Paul ${ }^{2}$, Amengle Albert Ludovic ${ }^{2}$, Nguidjoe EM ${ }^{3}$, Metogo Ntsama JA ${ }^{4}$, Tsafack \\ $\mathrm{E}^{3}$, Tochie Noutakdie Joel ${ }^{2 *}$ and Ze Minkande $\mathrm{J}^{2}$
}

${ }^{1}$ Department of Surgery and Specialties, University of Douala, Africa

2Department of Surgery and Specialties, University of Yaoundé I, Africa

${ }^{3}$ Department of Pharmacotoxicology and Pharmacokinetics, University of Yaoundé I, Africa

${ }^{4}$ Department of Gynecology and Obstetrics, University of Yaoundé I, Africa

Submission: July 25, 2019; Published: August 19, 2019

*Corresponding author: Joel Noutakdie T, Faculty of Medicine and Biomedical Sciences, University of Yaoundé I, Cameroon, Africa

\begin{abstract}
Objectives: Tramadol is an analgesic which can be used to relief of moderate to severe postoperative pain. It is a prodrug that requires bioactivation through cytochrome P450 enzymes (CYP450) to obtain 0-desmethyltramadol(M1) with is its most potent analgesic metabolite. However, little is known about the pharmacogenetic profile Africans with regards to tramadol metabolism. Hence, we aimed to study the biological efficacy of tramadol in an African population.

Patients and methods: This was a prospective cohort study over a 3-month period carried out at intensive care unit (ICU) of a tertiary hospital in Cameroon. We enrolled all consecutive consenting patients who had a moderate-to-severe pain surgery, who were fully conscious, and had not been administered drugs metabolized by CYP450.We studied their socio-demographic data, the type of surgery they underwent, and the technique of anesthesia used. Immediately after surgery, tramadol was administered at a dose of $2 \mathrm{mg} / \mathrm{kg}$ slow intravenously every 6 hours. Pain was evaluated using the Visual Analog Scale (VAS) on ICU admission and then at the $20^{\text {th }}$ minute, $3^{\text {rd }}$ hour, $6^{\text {th }}$ hour, $12^{\text {th }}$ hour, and $24^{\text {th }}$ hour respectively, following tramadol administration. Vital signs and side effects were also recorded. Plasma samples were collected at $3^{\text {rd }}$ and $6^{\text {th }}$ hours after tramadol administration to assay tramadol and M1 using HPLC-UV.

Results: We enrolled 30 patients with a mean age of 32 years operated for caesarean section, exploratory laparotomy and cancer surgery, mainly under spinal anesthesia and general anesthesia. Before administration of tramadol, the VAS was about 6/10. The VAS progressively decreased $4 / 10$ at the $3^{\text {rd }}$ hour, $1 / 10$ at the $6^{\text {th }}$ hour. The vital sign that varied the most was the respiratory rate with a reduction of 3 breath cycles per minute as early as the $6^{\text {th }}$ hour. The most common side effects were nausea and vomiting. Samples from 13 patients were analyzed. M1 was found in all patients; of which 4 had a slow metabolism and 3 had a faster metabolism. Overall, there was good correlation between clinical and biological findings.
\end{abstract}

Conclusion: Overall, there was good correlation between the clinical and biological analgesic efficacy of tramadol.

Keywords: postoperative analgesia; axillary ultrasound-guided block; perineural dexamethasone; lidocaine-bupivacaine

\section{Introduction}

Postoperative Pain is considered an undesirable and expected effect of surgery; hence, an effective postoperative analgesia regimen is considered indisputable. Tramadol is an effective analgesic for the relief of moderate to severe postoperative pain [1]. It has an original action profile on both weak opioid agonist on $\mu$ receptors, and as a reuptake inhibitor of norepinephrine and serotonin [2]. Tramadol is a prodrug that requires bioactivation to obtain 0-desmethyltramadol which has the analgesic effects of tramadol. This bioactivation is done through the hepatic enzyme (CYP2D6) of the cytochrome P450 family which has genetic polymorphisms. In the Caucasian population, $10 \%$ of people do not have CYP2D6 activity. Thus, tramadol will have no analgesic effect on them [3-5]. However, the pharmacokinetic and pharmacodynamic profiling of drugs ensures their rational use, providing a precise description of the dose-concentration- 
effect-toxicity relationships [6]. In our setting, few studies have been conducted on the clinical and pharmacological monitoring of analgesic drugs. Hence, we carried out this study on the therapeutic follow-up of tramadol in patients admitted in the postoperative period, in the intensive care unit (ICU) of the Yaoundé Gynecoobstetrics and Pediatric Hospital (HGOPY).

\section{Patients and Methods}

This was a prospective cohort study conducted over a 3-month period in the ICU of HGOPY, as well as in two laboratories. Sampling was consecutive and non-exhaustive. We included patients who underwent surgeries of moderate to severe pain, without altered consciousness, with no notion prior administration of drugs metabolised by CYP450 enzymes and with no hepatic or renal failure.

\section{Clinical evaluation}

Sociodemographic data, the type of surgery and the technique of anesthesia were studied. Tramadol was administered over 15 minutes at a dose of $2 \mathrm{mg} / \mathrm{kg}$ intravenously diluted in $100 \mathrm{ml}$ of infusion every 6h. Pain assessment with the Visual Analogue Scale. (VAS) was done at admission into the ICU and then at the 20thmin, 3rdh, 6thh, 12thh\& 24thh respectively, following tramadol administration. Clinical parameters and side effects were recorded. We collected $3-5 \mathrm{ml}$ of blood sample in EDTA tubes at the 3 rd \& 6th hour after administration of tramadol.

\section{Laboratory analysis}

The collected blood was centrifuged for 20 minutes at $4000 \mathrm{rpm}$ to extract the plasma in search for 0-desmethyltramadol.

\section{Plasma pre-treatment: liquid-liquid extraction}

In $500 \mu \mathrm{g}$ of plasma, we added a drop of $0.1 \mathrm{~mol} / \mathrm{L} \mathrm{NaOH}$. The mixture was vortexed for one minute. We added $1 \mathrm{ml}$ of extracted solvent which was made of ethylacetate + cyclohexane in the ratio of 1:4. The mixture was vortexed a second time for one minute and then centrifuged at 400rpm for 15 minutes. The organic phase obtained was then transferred to vials to be introduced into the autosampler.

\section{Preparation of the HPLC}

We used an HPLC-UV chain with RP C18 tubes with $5 \mu \mathrm{m}$ particles, $250 \times 4.6 \mathrm{~mm}$ PHENOMENEX $\AA$ brand. The eluent or mobile phase was acetonitrile/phosphate buffer (KH2PO4 0.01M solution) in proportions: 30/70 which was then mixed with triethylamine at a concentration of $0.1 \%$ TEA. The $\mathrm{pH}$ of this mobile phase was adjusted to 3 . The injection volume was $10 \mu \mathrm{l}$ with a flow rate of $1 \mathrm{ml} / \mathrm{min}$ and a separation time of 7 minutes. The detection was set at $218 \mathrm{~nm}$ UV at room temperature.

The data obtained was analyzed on the software SPSS version 20 and EPI INFO version 3.5.4. The statistical study was descriptive with the study of proportions and means.

\section{Results}

\section{Socio-demographic and clinical data}

We recruited 30 patients with a mean age of $32.8 \pm 10.26$ years. ASA 1 patients $(60 \%)$ were the most represented. Caesarean section was the most performed surgical procedure (80\%), followed by laparotomies (ectopic pregnancy and pelviperitonitis) and gynecological oncological surgeries. Spinal anesthesia (RA) was the most commonly performed anesthesia technique (54\%) followed by general anesthesia with orotracheal intubation (AG + IOT) in $43 \%$ of patients.

\section{The modalities of administration of tramadol}

Tramadol was averagely administered at a dose of $100 \mathrm{mg} /$ $\mathrm{kg}$ intravenously every 6 hours. It was always used in balanced analgesia with level 1 analgesics, mainly paracetamol (70\%).

\section{Assessment of pain before tramadol administration}

When evaluating the pain intensity of patients prior to tramadol administration, the mean VAS was $5,933 \pm 1,257$. The intensity of the pain was higher in patients who underwent exploratory laparotomy (6.3/10) (Figure 1). When the vital signs were taken, the respiratory rate was the only slightly elevated parameter varying up to 25 cycles/min (Table 1 ).

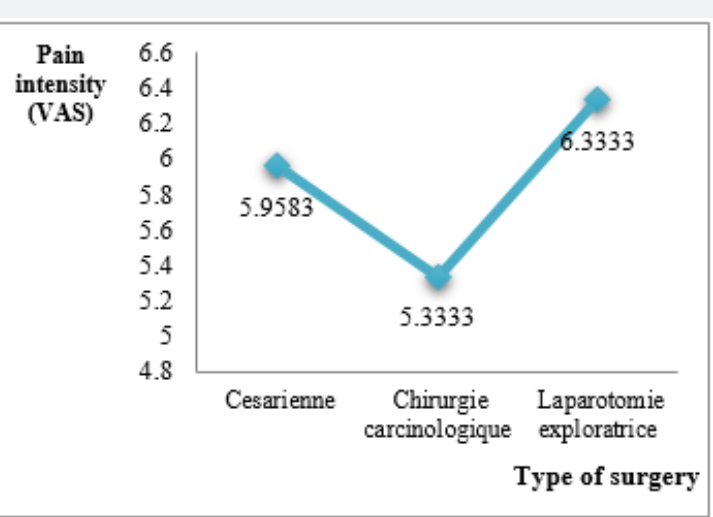

Figure 1: Evaluation of pain intensity before tramadol administration with respect to the type of surgery.

Table 1: Assessment of clinical parameters prior to tramadol administration.

\begin{tabular}{|c|c|c|c|c|}
\hline Parameters & Mean & Ecart-type & Minimum & Maximum \\
\hline SBP (mmHg) & 124.4667 & 15.2694 & 100 & 165 \\
\hline DBP (mmHg) & 75.3333 & 12.455 & 50 & 100 \\
\hline HR (beats/min) & 85.1 & 15.4124 & 52 & 120 \\
\hline RR (cycles/min) & 21.7667 & 4.2074 & 14 & 35 \\
\hline
\end{tabular}

SBP: Systolic blood pressure; DBP: Diastolic blood pressure; RR: Respiratory rate; HR: Heart rate.

\section{Assessment of pain following tramadol administration}

After administration of tramadol, a reduction in pain intensity was observed as early as the 20th minute. This reduction was 2 points or around 3/10 for all patients at the $3 \mathrm{rdh}$ compared to the 
intensity of the pain before the administration of tramadol. From the 24 thh, the VAS was about $1 / 10$ (Figure 2).

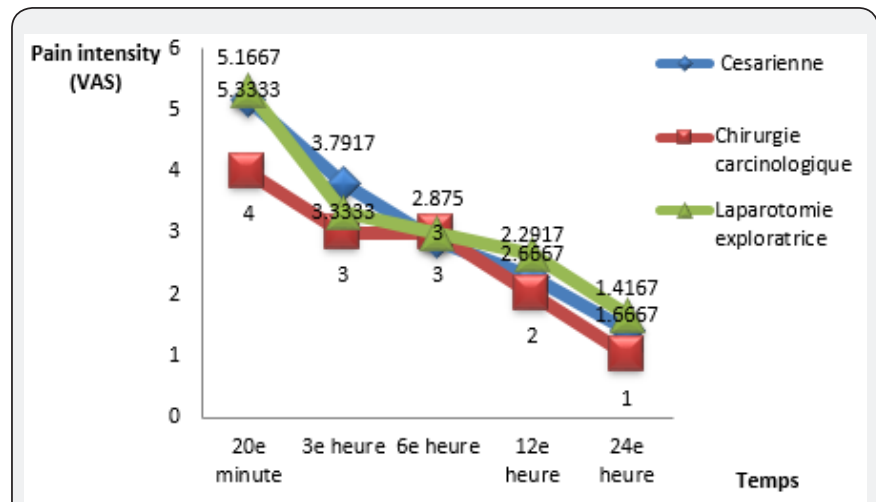

Figure 2: Evaluation of intensity after tramadol administration.

During the evaluation of the parameters, a decrease in systolic blood pressure of $20 \mathrm{mmHg}$ was observed at the $3 \mathrm{rdh}$ \& 6thh respectively for patients who underwent an exploratory laparotomy and a carcinological surgery. Concomitantly, a regression of $10 \mathrm{mmHg}$ was recorded for diastolic blood pressure. We observed a regression of 2 to 3 respiratory cycles per minute for all patients and 10 beats per minute reduction in pulse rate.

The main adverse effects of tramadol concerned mainly the gastrointestinal tract $(30 \%$ of nausea cases and $13.30 \%$ of vomiting cases), followed by cholinergic effects (dryness of mouth in $16.7 \%$ of cases) and neurological effects especially vertigo $(3.30 \%)$.

\section{Plasma determination of 0 -desmethyltramadol}

When we performed the plasma determination of 13 patients. We found the active metabolite of tramadol: O-desmethyltramadol (M1). Overall, there was good agreement between clinical and laboratory data (Figure 3). However:

Four patients had a slower metabolism (Table 2)

Three patients had a faster metabolism (Table 3)

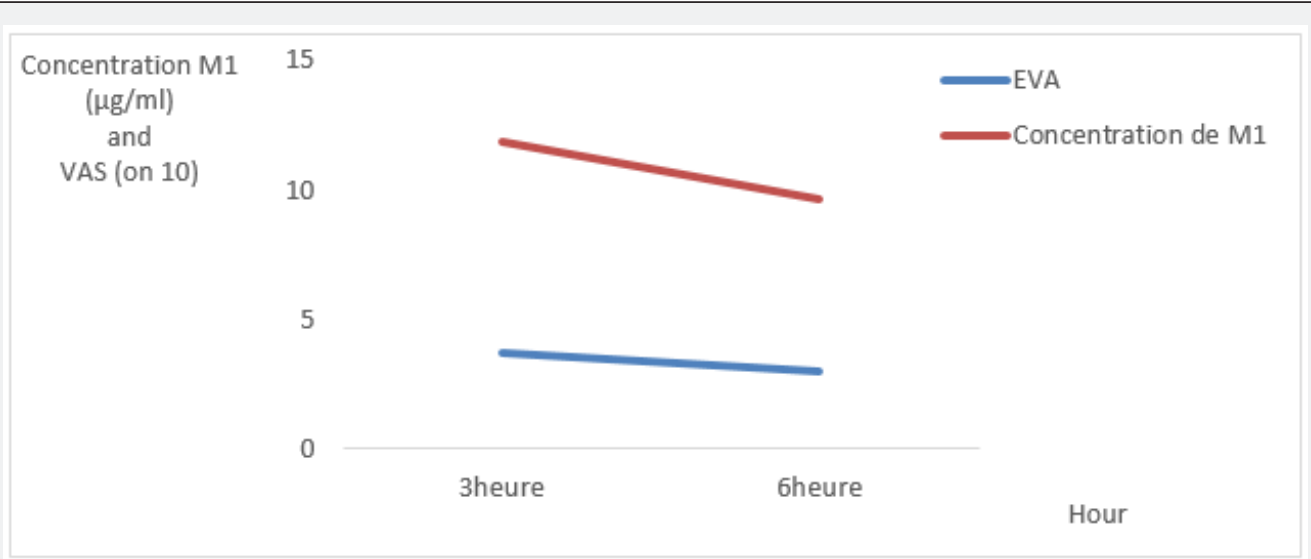

Figure 3: Relationship between the VSA and M1 concentration

Table 2: Relationship of VAS and biological assay in patients with slow metabolism.

\begin{tabular}{|c|c|c|c|c|}
\hline & Patient 1 & Patient 2 & Patient 3 & Patient 4 \\
\hline VAS at the $3^{\text {rd }}$ & 7 & 5 & 6 & 4 \\
\hline VAS at the $6^{\text {th }}$ & 5 & 3 & 5 & 3 \\
\hline M1 Concentration at the $3^{\text {rd }} \mathrm{h}(\mu \mathrm{g} / \mathrm{ml})$ & 3.28 & 12.53 & 13.53 & 15.53 \\
\hline M1 Concentration at the $6^{\text {th }} \mathrm{h}(\mu \mathrm{g} / \mathrm{ml})$ & 3.15 & 11.82 & 35.11 & 24.43 \\
\hline
\end{tabular}

Table 3: Relationship between VAS and biological assay in patients with rapid metabolism.

\begin{tabular}{|c|c|c|c|}
\hline & Patient 1 & Patient 2 & Patient 3 \\
\hline VAS at the 3 rdh & 4 & 6 & 5 \\
\hline VAS at the 6 thh & 1 & 5 & 5 \\
\hline M1 Concentration at the $3 \mathrm{rdh}(\mu \mathrm{g} / \mathrm{ml})$ & 14.53 & 16.53 & 17.53 \\
\hline M1 Concentration at the 6thh $(\mu \mathrm{g} / \mathrm{ml})$ & 3.53 & 2.46 & 1.96 \\
\hline
\end{tabular}

\section{Discussion}

The average age of our patients was $32.8 \pm 10.26$ years, which corresponds to the generally young age of the Cameroonian and
African population. Caesarean sections were most performed surgical procedures explained by the fact that the study setting is a hospital specialized only in the management of mother and child pathologies. 
Paracetamol was the main analgesic used in combination with tramadol. In effect, the pain after caesarean section, exploratory laparotomy or cancer surgery is classified as strong in the first 48 hours according to the WHO [7]. As such, it seems logical to propose tramadol as part of a balanced intravenous analgesic regimen [2]. In addition, with respect to the combination of tramadol + paracetamol, a meta-analysis of randomized clinical trials conducted on postoperative dental, orthopedic and gynecological pain showed the analgesic superiority of tramadolparacetamol compared to the either analgesic effect tramadol or paracetamol [8].

The mean VAS before tramadol administration was $5.933 \pm 1.257 / 10$, explained by the fact that preemptive analgesia was started during the intraoperative period. A significant reduction in pain intensity was observed for all patients at the $3 \mathrm{rdh}$ compared to the intensity of the pain before administration of tramadol. This reduction is more than $50 \%$ at the 24 thh compared to the baseline VAS before administration of tramadol. This threshold significance was proposed in 2003. These data seem to agree with the pharmacokinetic data with respect to the time of action, the half-life and the plasma peak of tramadol [6].

With regards to the side effects of tramadol, we mainly found the gastrointestinal (nausea, vomiting), cholinergic effects (dryness of mouth) and vertigo. This finding concurs with that of the literature [6]. Of the 30 patients enrolled, 13 had postoperative biological monitoring of the concentration of tramadol and 0-desmethyltramadol or M1 at the 3rd \& 6thh after administration of tramadol. Overall, there was good agreement between clinical and biological parameters. An African study in Ethiopia [9] was previously performed without the biological assay of tramadol. Our results are in line with this study as far as patient satisfaction is concerned.

We wanted to go further than this by testing the hypothesis that patient satisfaction using VAS may be consistent to some extent with the biology of tramadol and O-desmethyltramadol. We found that those who metabolize slowly have better satisfaction with the analgesic effect. On the other hand, in those who seemed to metabolize rapidly, the VAS decreased but remained generally at levels of moderate pain values. This is in good correspondence with the literature on the subject [10].

We will have been able to have more samples tested, to measure more specific pharmacokinetic parameters such as the area under the curve, the plasma clearance and the half-life, for example [11]. Nevertheless, our results allow us to know the metabolism profiles (CYP 2D6) of our patients indirectly. In addition, tramadol + paracetamol combination could compensate for the effect of tramadol on VAS values, if tramadol shows low plasma concentrations at the same time.

\section{Conclusion}

In our cohort made up of a young population, we obtained a good analgesic efficacy of tramadol at the biologically and clinically; highlighting the metabolic profile of our patients.

\section{Acknowledgment}

The authors thank all patients who partook in this study and wish to thank all the staff of the participating hospitals for their commitment in patient care.

\section{References}

1. (1997) SFAR-Prise en charge de la douleur post opératoire chez l'adulte et l'enfant. Conférence de consensus.

2. Marc E Gentili, Marcel Chauvin (2004) Tramadol dans la prise en charge de la douleur postopératoire: pour quelle indication? Le Courrier de l'algologie 3(2).

3. Poulsen L, Arendt Nielsen L, Brosen K, Sindrup SH (1996) The hypoalgesic effect of tramadol in relation to CYP2D6. Clin Pharmacol Ther 60(6): 636-644.

4. Pedersen RS, Damkier P, Brosen K (2006) Enantioselective pharmacokinetics of tramadol in CYP2D6 extensive and poor metabolizers. Eur J Clin Pharmacol 62(7): 513-521.

5. Stamer UM, Lehnen K, Hothker F, Bayerer B, Wolf S, et al. (2003) Impact of CYP2D6 genotype on postoperative tramadol analgesia. Pain 105(1-2): 231-238.

6. Scott LJ, Perry CM (2000) Tramadol: A review of its use in perioperative pain. Drugs 60(1): 139-176.

7. (1998) Société française d'anesthésie et de réanimation. Conférence de consensus. Recommandations du jury. Prise en charge de la douleur postopératoire chez l'adulte et l'enfant. Ann Fr Anesth Réanim 17: 445461.

8. McQuay H, Edwards J (2003) Meta-analysis of single dose oral tramadol plus acetaminophen in acute postoperative pain. Eur J Anaesthesiol Suppl 28: 19-22.

9. Raffa RB, Friderichs E, Reimann W, Shank RP, Codd EE, et al. (1992) Opioid and nonopioid components independently contribute to the mechanism of action of tramadol, an 'atypical' opioid analgesic. J Pharmacol Exp Ther 260(1): 275-285.

10. Woldehaimanot TE, Eshetie TC, Kerie MW (2014) Postoperative pain management among surgically treated patients in an ethiopian hospital. Plos One 9(7): 1-9.

11.Xu J, Zhang XC, Lv XQ Xu YY, Wang GX, et al. (2014) Effect of the cytochrome P450 2D6*10 genotype on the pharmacokinetics of tramadol in post-operative patients. Pharmazie 69(2): 138-141. 
This work is licensed under Creative Commons Attribution 4.0 License

DOI: 10.19080/JAICM.2019.09.555760
Your next submission with Juniper Publishers will reach you the below assets

- Quality Editorial service

- Swift Peer Review

- Reprints availability

- E-prints Service

- Manuscript Podcast for convenient understanding

- Global attainment for your research

- Manuscript accessibility in different formats ( Pdf, E-pub, Full Text, Audio)

- Unceasing customer service

Track the below URL for one-step submission https://juniperpublishers.com/online-submission.php 